\title{
Answer to the Letter to the Editor of A. Hidalgo-Ovejero concerning "Intradural lumbar disc herniation: report of five cases with literature review" (by L. G. Ducati, M. V. Silva, M. M. Brandão, F. R. Romero, M. A. Zanini; Eur Spine J. doi:10.1007/s00586-012-2631-2)
}

\section{Luis Gustavo Ducati}

Accepted: 16 December 2012/Published online: 4 January 2013

(c) Springer-Verlag Berlin Heidelberg 2013

Dear Editor,

We appreciate the observations made by A. HidalgoOvejero about his works on the presence of intraspinal or intradiscal gas. However, the main purpose of our paper was not only to describe the difficulties of diagnosis, but mostly to show the particularities of the surgical treatment. So, we focused the discussion mostly in the surgical aspects, the techniques and its pitfalls. Besides, among our five cases, we did not have any patient with this radiological finding.
We consider the features described by A. HidalgoOvejero and the other authors extremely important in terms of prediction of an intradural herniation preoperatively, so in the presence of these signs, the surgeon must prepare himself to deal with intradural lesion. It is really an important issue that improves consistently our observations, mostly in terms of neuroimaging.

Conflict of interest None. 